\title{
Can the modeling for simplification of a dental implant surface affect the accuracy of 3D finite element analysis?
}

Fellippo Ramos Verri, Ronaldo Silva Cruz, Victor Eduardo de Souza Batista, Daniel Augusto de Faria Almeida, Ana Caroline Gonçales Verri, Cleidiel Aparecido de Araújo Lemos, Joel Ferreira Santiago Júnior \& Eduardo Piza Pellizzer

To cite this article: Fellippo Ramos Verri, Ronaldo Silva Cruz, Victor Eduardo de Souza Batista, Daniel Augusto de Faria Almeida, Ana Caroline Gonçales Verri, Cleidiel Aparecido de Araújo Lemos, Joel Ferreira Santiago Júnior \& Eduardo Piza Pellizzer (2016) Can the modeling for simplification of a dental implant surface affect the accuracy of 3D finite element analysis?, Computer Methods in Biomechanics and Biomedical Engineering, 19:15, 1665-1672, DOI: 10.1080/10255842.2016.1176156

To link to this article: https://doi.org/10.1080/10255842.2016.1176156

曲 Published online: 15 Apr 2016.

Submit your article to this journal ¿

Џll Article views: 206

View Crossmark data ¿

Citing articles: 10 View citing articles $\square$ 


\title{
Can the modeling for simplification of a dental implant surface affect the accuracy of 3D finite element analysis?
}

\author{
Fellippo Ramos Verria, Ronaldo Silva Cruz ${ }^{\mathrm{a}}$, Victor Eduardo de Souza Batista ${ }^{\mathrm{a}}$, Daniel Augusto de Faria Almeidaa, \\ Ana Caroline Gonçales Verrib ${ }^{b}$ Cleidiel Aparecido de Araújo Lemosa ${ }^{a}$, Joel Ferreira Santiago Júnior ${ }^{c}$ and \\ Eduardo Piza Pellizzera \\ aDepartment of Dental Materials and Prosthodontics, Aracatuba Dental School, UNESP - Univ Estadual Paulista, Aracatuba, Brazil; ${ }^{\mathrm{b} D e p a r t m e n t}$ \\ of Pediatric and Community Dentistry, Aracatuba Dental School, UNESP - Univ Estadual Paulista, Aracatuba, Brazil; 'Department of Health \\ Sciences, Sacred Heart University, Bauru, Brazil
}

\begin{abstract}
The aim of this study was to assess stress/strain of different implant modeling simplifications by 3D-FEA. Three variation of external hexagon implant $(\varnothing 3.75 \times 10 \mathrm{~mm})$ supporting one molar crown were simulated: A (no threads); B (slightly threads simplification); C (original design). $200 \mathrm{~N}$ (axial) and $100 \mathrm{~N}$ (oblique) were applied. Cortical bone was evaluated by maximum principal stress and microstrain qualitatively and quantitatively (ANOVA and Tukey post hoc $(p<0.05)$ ). Higher stress levels $(p<0.05)$ were observed in model A. Models B and C presented similar stress transmission. It was possible to conclude that slightly simplification should be used for studies evaluating stress transferring for bone tissue.
\end{abstract}

\section{ARTICLE HISTORY}

Received 16 December 2015

Accepted 5 April 2016

\section{KEYWORDS}

Dental implants; finite element analysis;

biomechanics

\section{Introduction}

The process of osseointegration can be affected by the interaction between biological and mechanical factors varying from bone quality to the treatment of the implant surface. Therefore, the understanding of the influence of these factors in implant-supported rehabilitation must be improved in order to obtain better clinical results (Chung et al. 2008).

In this context, biomechanical studies have been used in different areas of dentistry to improve understanding of the relationship between dental restorative materials and buccal tissues (Choi et al. 2014). Nowadays, different methodologies are used to assess the biomechanics - under static loads - in the implantology, such as photoelasticity (Pellizzer et al. 2014), digital image correlation (Tiossi et al. 2013), strain gauge (Sallam et al. 2012), and finite element analysis, or FEA (Dayrell et al. 2015).

Several scientific works use FEA in implantology (Liang et al. 2015; Lofaj et al. 2015; Ramos Verri et al. 2015; SottoMaior et al. 2016). These works describe different methodological steps to obtain the 3D model. Consequently, each work might generate different results when the same situation is tested. The accuracy of FEA can be influenced by factors such as the geometric detail of the object to be modeled and analyzed (i.e. surface simplification), the applied boundary conditions, the functional loading, and the mechanical properties of materials (Choi et al. 2014). On the issue of surface simplification in implantology, different techniques are used to simulate the surface of an implant using the computer-aided design (CAD) provided by the implant company. These include total elimination of the threads (smoothed surface) (Barão et al. 2013), slight simplification of the implant but sustaining the threads (Ramos Verri et al. 2015), and no simplification of the implants or threads (Pessoa et al. 2014). However, the literature does not describe how much of this simplification can be performed without losing the accuracy of the analysis.

Based on the topics above, the aim of this study was to use FEA 3D to assess the different types of modeling used in the literature for simplification of an implant surface and the influences these modeling types have on the stress/ strain distributions on the bone tissue around implant. The present study tests the hypothesis that the modeling technique for simplifying an implant surface can modify the stress/strain distribution on the cortical bone. 


\section{Material and methods}

\section{Experimental design}

This research follows the methodology of previous studies (de Faria Almeida et al. 2014; Moraes et al. 2015; Ramos Verri et al. 2015). Three 3D models varying the simplification of the implant surface were simulated with two load variations (Table 1).

\section{Three-dimensional modeling}

Each 3D model was composed of a mandibular bone section relative to the second molar region and an external hexagon implant of $\varnothing 3.75 \times 10 \mathrm{~mm}$ (Conexão Sistemas de Protese Ltda., Aruja, SP, Brazil), supporting a screwretained single crown.

The bone tissue was composed of trabecular bone in the center, surrounded by a $1 \mathrm{~mm}$ layer of cortical bone. The bone tissue was obtained using decomposition of the computerized tomography with InVesalius software (CTI, Campinas, SP, Brazil) and surface simplification with Rhinoceros $4.0^{\circ}$ software (NURBS Modeling for Windows, Seattle, WA, USA).

The modeling of the implant was performed with three variations: model $\mathrm{A}$, a total elimination of the threads in the CAD (smoothed surface); model B, a slight simplification of the implant sustaining the threads in the CAD; and model $\mathrm{C}$, no simplification of the implant or threads in the CAD (Figure 1). The abutment (UCLA, Conexão Sistemas de Protese Ltda., Aruja, SP, Brazil) and feldspathic porcelain simulated were the same for all situations compatible to the implant type.

Implants, abutments, crowns, and fixation screws were simplified using SolidWorks 2010 (SolidWorks Corp*, Waltham, MA, USA) and Rhinoceros $4.0^{\circ}$. The software was the same for all models. Finally, all geometries were exported for discretization in the finite element software FEMAP 11.1.2 (Siemens PLM Software Inc., Santa Ana, CA, USA).

\section{Three-dimensional FE configuration}

The FEMAP $11.1 .2^{\circ}$ software was used to do the finite element models in pre- and post-processing steps. In the pre-processing step, meshes using tetrahedral parabolic solid elements were generated (Figure 1). The number of nodes and elements for each model is illustrated in the Table 2. All mechanical properties of each simulated material were attributed to the meshes using values from the literature (Table 3). All materials were considered isotropic,

Table 1. Specifications of the models.

\begin{tabular}{|c|c|c|c|}
\hline Model & Loading & Description & Nodes/Elements \\
\hline 1 & & Dental implant $(3.75 \times 10 \mathrm{~mm})$, external hexagon, simplification with total elimination of the threads & $461.677 / 308.917$ \\
\hline 2 & Axial & Dental implant $(3.75 \times 10 \mathrm{~mm})$, external hexagon, slight simplification of the implant sustaining the threads & $462.059 / 305.609$ \\
\hline 3 & & Dental implant $(3.75 \times 10 \mathrm{~mm})$, external hexagon, no simplification in the thread & $597.768 / 364.982$ \\
\hline 4 & & Dental implant $(3.75 \times 10 \mathrm{~mm})$, external hexagon, simplification with total elimination of the threads & $461.677 / 308.917$ \\
\hline 5 & Oblique & Dental implant $(3.75 \times 10 \mathrm{~mm})$, external hexagon, slight simplification of the implant sustaining the threads & $462.059 / 305.609$ \\
\hline 6 & & Dental implant $(3.75 \times 10 \mathrm{~mm})$, external hexagon, no simplification in the thread & $597.768 / 364.982$ \\
\hline
\end{tabular}
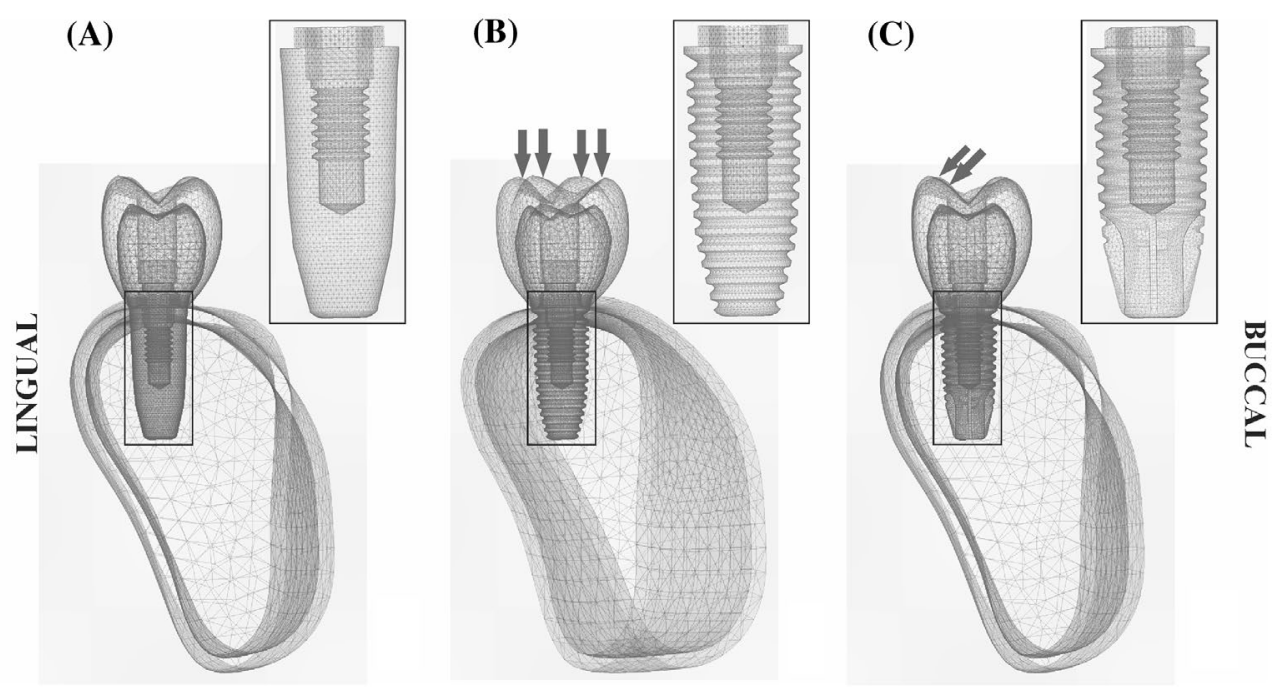

Figure 1. Mesh of generated models simulating a real clinical situation, mesial view: (A) simplification with total elimination of the threads in the CAD; (B) slight simplification of the threads in the CAD, arrows illustrating the axial load of $200 \mathrm{~N}, 50 \mathrm{~N}$ at each cusp tip; (C) no simplification of the threads in the CAD, arrows illustrating the oblique load of $100 \mathrm{~N}, 50 \mathrm{~N}$ at each lingual cusp tip. 
Table 2. Mechanical properties of materials used in model.

\begin{tabular}{lccc}
\hline Structures & Elastic modulus $(\lambda)(G P a)$ & Poisson ratio $(v)$ & References \\
\hline Trabecular bone & 1.37 & 0.3 & (Ramos Verri et al. 2015) \\
Cortical bone & 13.7 & 0.3 & (Ramos Verri et al. 2015) \\
Titanium (implant) & 110.0 & 0.35 & $($ Ramos Verri et al. 2015) \\
NiCr alloy & 206.0 & 0.33 & (Eraslan et al. 2005) \\
Feldspathic porcelain & 82.8 & 0.35 & (Ramos Verri et al. 2015) \\
\hline
\end{tabular}

Table 3. Values of the mean and standard deviation of the maximum principal stress and microstrain on bone tissue.

\begin{tabular}{llc}
\hline & & \multicolumn{2}{c}{ Mean/ Standard deviation } \\
\cline { 3 - 3 } Models & Loading & Maximum principal stress \\
\hline A - simplification with total elimination of the threads & Axial & $-0.435 \pm 0.263$ \\
B - slight simplification of the implant sustaining the threads & Axial & $-0.244 \pm 0.168$ \\
C - no simplification in the thread & Axial & $-0.235 \pm 0.180$ \\
A - simplification with total elimination of the threads & Oblique & $0.000337 \pm 0.0000670$ \\
B - slight simplification of the implant sustaining the threads & Oblique & $0.000151 \pm 0.0000310$ \\
C - no simplification in the thread & Oblique & $0.00112 \pm 0.000773$ \\
\hline
\end{tabular}

*Values $\times 10^{-6}$

homogeneous, and linearly elastic. In the post-processing step, the FEMAP software was utilized for reading and plotting of stress and strain maps obtained by the mathematical calculations using the NEi Nastran $11.1^{\circ}$ software (Noran Engineering, Inc., Westminster, CA, USA), which will be described in more detail in the $\mathrm{FE}$ analysis section.

\section{Interface conditions, boundary conditions, and loading}

The interface conditions were also simulated in the pre-processing step. Thus, abutment/implant penetration types were assumed as symmetric contact (by NeiNastran analysis) and all other contacts (cortical bone/trabecular bone; cortical bone/implant; trabecular bone/implant; internal implant threads/screw treads; screw seating surface/abutment seating surface; abutment/feldspathic ceramic) were assumed as symmetric welded (by NeiNastran analysis). The boundary conditions were fixed in all axes $(x, y$, and $z)$ at both bone block sections (anterior and posterior faces) (Ramos Verri et al. 2015). To simulate a real clinical situation, the applied force was $200 \mathrm{~N}$ axially, with $50 \mathrm{~N}$ at each cusp tip, and $100 \mathrm{~N}$ obliquely, with $50 \mathrm{~N}$ at each lingual cusp tip (Ramos Verri et al. 2015) (Figure 1(c)).

\section{FE analysis}

To obtain the results, all analyses were processed using NEi Nastran $11.1^{\circ}$ software. The processing analysis of the models was performed on a workstation (HP Workstation Z200, São Paulo, Brazil) with the following characteristics: Intel ${ }^{\circ} \mathrm{Xeon}{ }^{\circ}$ processor $\mathrm{x} 3470,16 \mathrm{~GB}$ of RAM, and $2 \mathrm{~TB}$ of HD. After the analyses, the results were transferred to the FEMAP $11.1 .2^{\circ}$ software for graphic visualization of the stress and strain maps of the cortical bone tissue.
Maximum principal stress maps and microstrain maps $\left(\mu\right.$-strain or strain $\times 10^{-6}$ ) were used to evaluate the cortical bone tissue surrounding the dental implant. The unit of measurement in this study was the megapascal ( $\mathrm{MPa})$ to maximum principal stress.

\section{Statistical analysis}

Analysis of variance (ANOVA) and the Tukey post hoc test were performed to verify the influence of different modeling types on stress/strain distributions for the cortical bone tissue. Sigma Plot 12.3 (Systat Software Inc., San Jose, CA, USA) performed all statistical analyses and values of $p<0.05$ were considered statistically significant, according to studies in the literature (de Faria Almeida et al. 2014; Ramos Verri et al. 2015).

\section{Results}

\section{Maximum principal stress on cortical bone}

The modeling modified the stress distribution on the cortical bone tissue $(p<0.001$; Figure 2$)$. Under axial loading, models $\mathrm{B}$ and $\mathrm{C}$ showed similar compressive stress distribution $(p=0.974)$, but model A showed a different pattern of stress distribution (A vs. B, $p<0.001$; A vs. C, $p<0.001$; Figure 3).

The oblique load statistically increased the stress for all models $(p<0.001$; Figure 2). Furthermore, of the three models, model A showed the highest stress values on the cortical bone tissue surrounding the dental implant (A vs. $\mathrm{B}, p=0.004$; A vs. $\mathrm{C}, p=0.004$; Figure 4 ), particularly the traction stress $(p<0.001$; Figure 5). Nevertheless, models B and $\mathrm{C}$ showed similar biomechanical behavior $(p=0.996$; Figures 4 and 5). The mean and standard deviation values can be seen in Table 3 . 


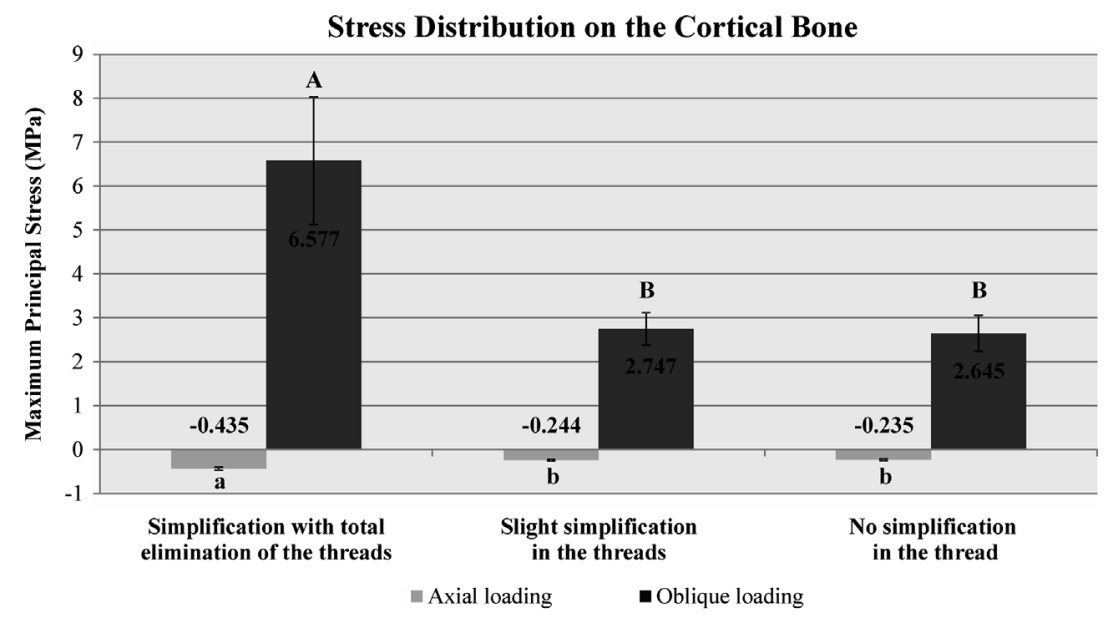

Figure 2. Mean and standard error values for the maximum principal stress on the cortical bone.

Notes: Differences between uppercase and lowercase letters indicate statistically significant results $(A, a ; B, b)$. Equal letters indicate no statistically significant results $(\mathrm{b}, \mathrm{b} ; \mathrm{B}, \mathrm{B})$.

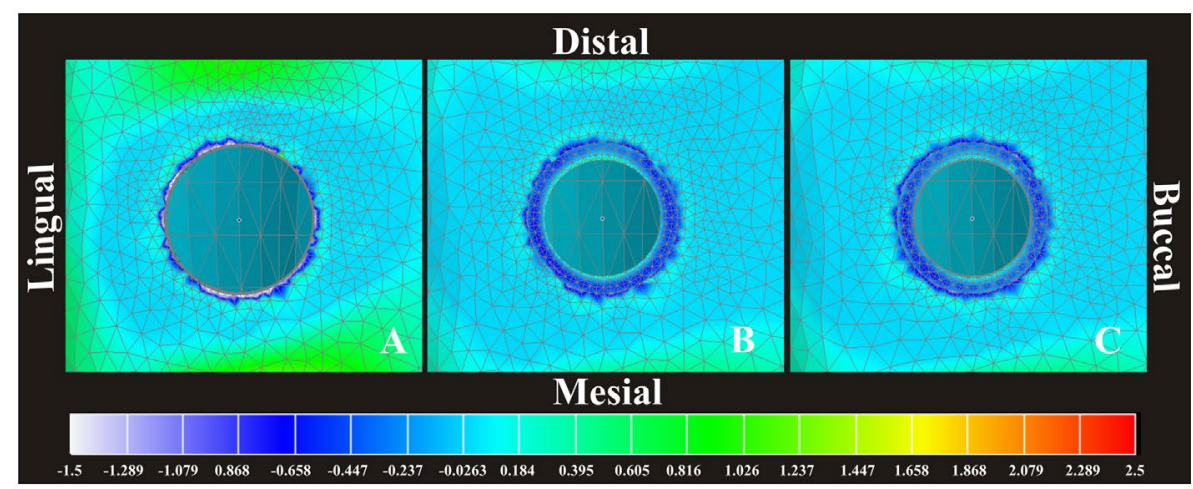

Figure 3. Maximum principal stress for axial loading, occlusal view. (A) simplification with total elimination of the threads in the CAD; (B) slight simplification of the threads in the CAD; (C) no simplification of the threads in the CAD.

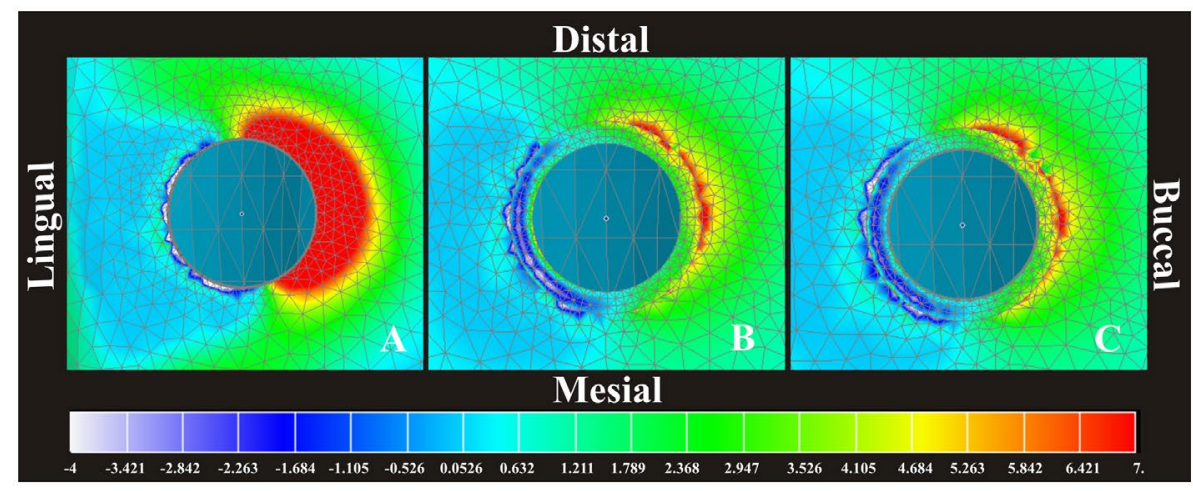

Figure 4. Maximum principal stress maps for oblique loading, occlusal view. (A) simplification with total elimination of the threads in the CAD; (B) slight simplification of the threads in the CAD; $(C)$ no simplification of the threads in the CAD.

\section{Microstrain on cortical bone}

Compared to the other models, model A statistically increased the microstrain on the cortical bone tissue surrounding the dental implant under axial loading (A vs. B, $p=0.038$; A vs. C, $p=0.039$, Figure 6), but models B and C showed no statistically significant difference $(p=1.000)$.
For all models, the oblique loading increased the microstrain on the cortical bone tissue compared to axial loading ( $p<0.001$; Figure 7$)$. Furthermore, the microstrain increase in model A was statistically significant compared with that of models B $(p<0.001)$ and C $(p<0.001)$. However, there was no statistically significant 


\section{Traction and Compression Stress on the Cortical Bone}

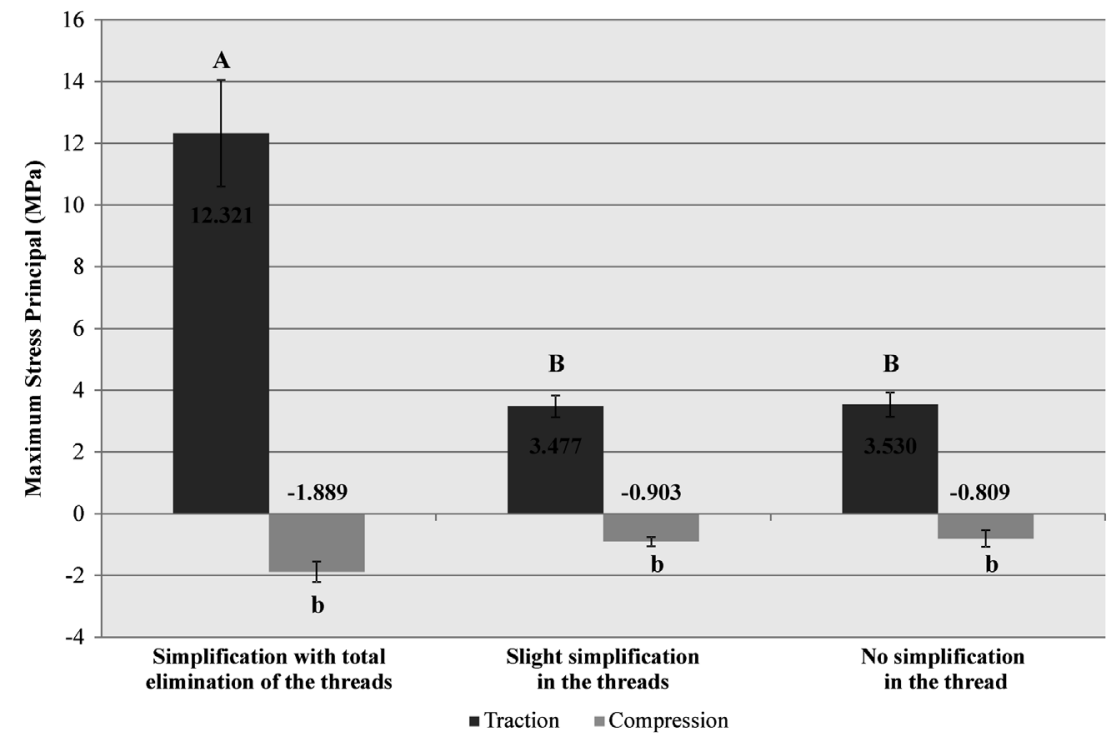

Figure 5. Mean and standard error values for the maximum principal stress on the cortical bone, analysis of traction stress and compressive stress under oblique loading.

Notes: Different uppercase letters indicate statistically significant results $(A, B)$. Equal uppercase letters indicate no statistically significant results $(B, B)$. Equal lowercase letters indicate no statistically significant results $(b, b)$.

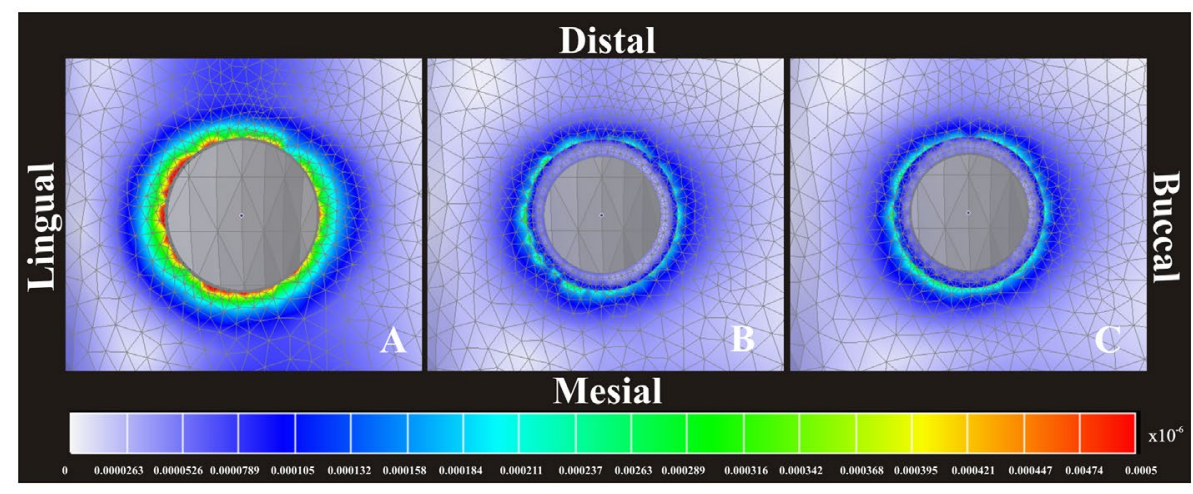

Figure 6. Mean and standard error values for microstrain on the cortical bone.

Notes: Differences between uppercase and lowercase letters indicate statistically significant results $(A, a ; B, b)$. Equal letters indicate no statistically significant results $(b, b ; B, B)$.

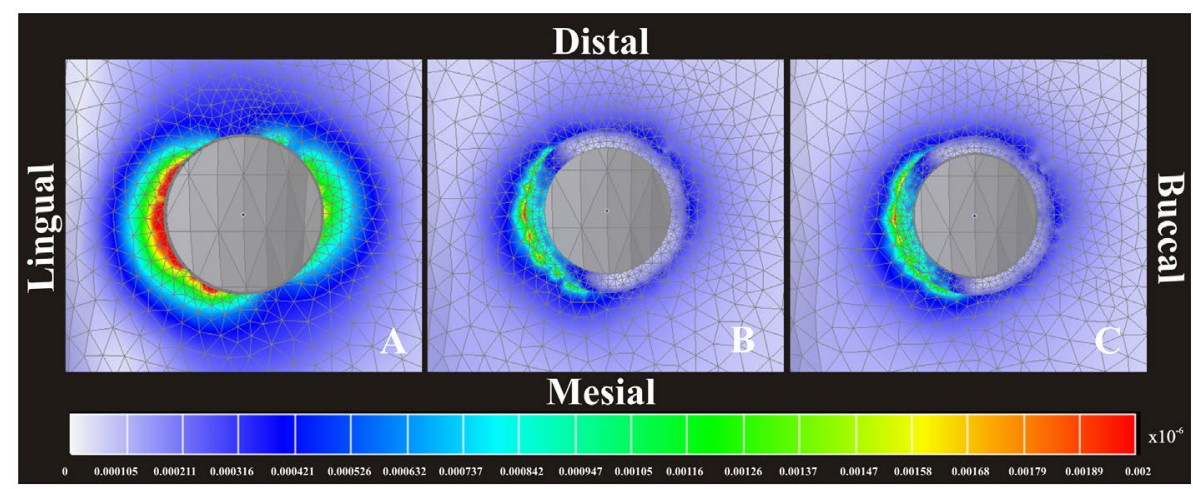

Figure 7. Microstrain maps for axial loading, occlusal view. (A) simplification with total elimination of the threads in the CAD; (B) slight simplification of the threads in the CAD; $(C)$ no simplification of the threads in the CAD. 


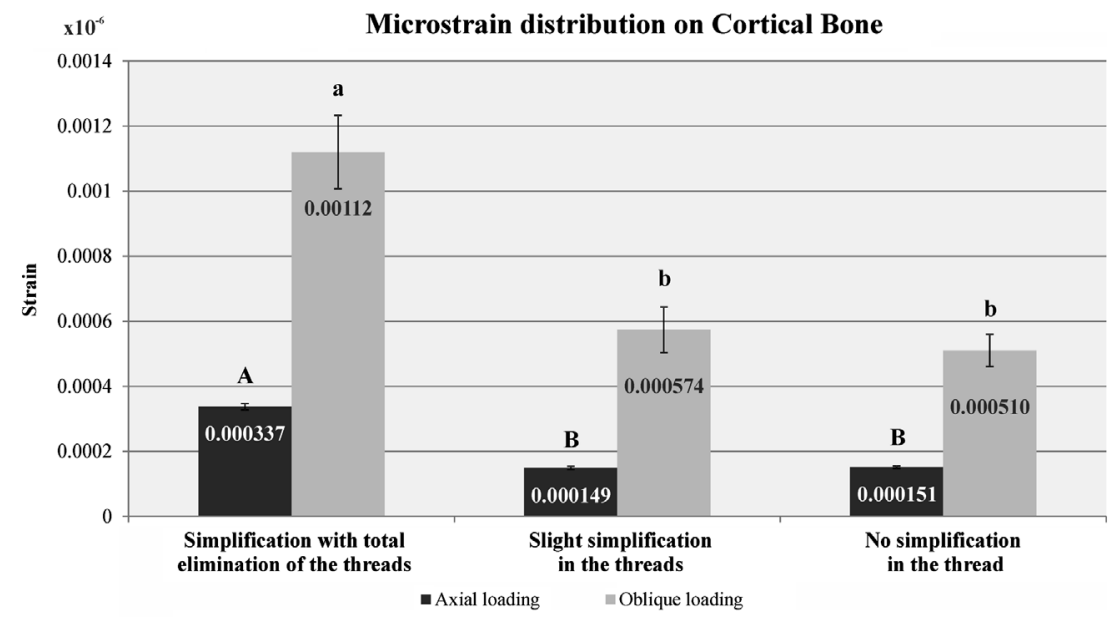

Figure 8. Microstrain maps for oblique loading, occlusal view. (A) simplification with total elimination of the threads in the CAD; (B) slight simplification of the threads in the CAD; (C) no simplification of the threads in the CAD.

difference between models B and C ( $p=0.703$; Figure 8$)$. The mean and standard deviation values can be seen in Table 3.

\section{Discussion}

The modeling technique modified the stress and strain values on the cortical bone tissue around the implant when a major alteration - the total elimination of the threads - was performed (model A), but a slight simplification in the thread (model B) showed no statistically significant difference compared to no simplification in the thread (model C). Thus, the hypothesis of study was partially accepted. This can be justified because the threads increase the contact area between the implant and bone, helping dissipate interfacial stresses (Huang et al. 2007, 2008). Another factor is the major shear force in model A, since the threads offer stouter resistance to the shear force by increasing surface friction (Huang et al. 2008); this alters the stress and strain distribution on the bone/ implant interface (Matsunaga et al. 2013).

Our results showed similar stress and strain distribution on cortical bone tissue between models B and C even though there was a slight difference between the mean values obtained (Table 4). It is probably due to changes in the threads of the implant. The difference between the mean values obtained is justified by the simplification of the apical area of the implant. In this context, the literature has shown differences in the stress distribution among different thread shapes; however, the studies performed macro alteration in the thread shapes (e.g. square and triangular threads) in addition to alteration in the body implant (e.g. stepped and tapered bodies) (Huang et al. 2007; Chowdhary et al. 2013; Fuh et al. 2013).
Oblique loading increased the stress and strain on the cortical bone tissue, mainly in model A (with total elimination of the threads). In this context, studies that used FEA to evaluate the biomechanical behavior of dental implants have related that oblique loading is more harmful (de Faria Almeida et al. 2014; Moraes et al. 2015; Ramos Verri et al. 2015). We believe increased stress and strain from oblique loading in model $\mathrm{A}$ is due to the decrease of bone/implant contact area (Huang et al. 2007, 2008), as well as the major shear force (Huang et al. 2008) previously described. Additionally, the implant format (smoothed) leads to a higher shear friction than threated surfaces.

However, analyzing the stress and strain maps can be observed that the major difference between models is always constricted around the implant neck. It was reported that marginal bone loss might be partially caused by a high stress concentration in this region (Hoshaw et al. 1994; Kitamura et al. 2004). In this way, considering results of our study mathematical analysis of implant/bone interface should not to use totally simplified implant surface. However, if the focus of biomechanical study is not the bone/implant interface it is possible the use of a simplified implant surface since stress and strain distribution fair from implant were similar for all models.

Experiments can be replicated with a good level of accuracy using 3D FEA, consequently, this method is potentially useful as a preclinical assessment (Limbert et al. 2010). In our study, the materials were considered isotropic, homogeneous, and linearly elastic, as in previous studies (Moraes et al. 2015; Ramos Verri et al. 2015); however, it is known that bone tissue is inhomogeneous and anisotropic (Limbert et al. 2010; de Faria Almeida et al. 2014). Recent studies report the registration procedure between the microtomography scanbased Stereolithography descriptions of the peri-implant 
mandibular bone, thus improving the accuracy of the analysis by simulating more realistic bone tissue (Limbert et al. 2010; Kinoshita et al. 2013). However, further studies are necessary to disseminate and improve this technique. Furthermore, this technique demands higher computational capacity as well as a nonlinear analysis. Thus, as the purpose of this study was to assess the viability of simplifications that do not tend to change the result of biomechanical studies performed by this methodology, the use of linear analysis appears to be effective for this purpose.

A limitation of the study is the analysis of different threads simplification techniques in only one implant design and one bone type. The literature reports that internal connection and external connection showed different patterns of stress distribution (de Faria Almeida et al. 2014). Moreover, different types of bone can modify stress distribution patterns (Xiao et al. 2011). Thus, these variables should be evaluated in future studies for a better understanding of thread simplification on 3D FEA results.

Indeed, the option of modeling the simplification or total elimination of the threads facilitates the execution of study from modeling in simplification programs (e.g. SolidWorks and Rhinoceros ${ }^{\circ}$ ) to processing the data (Barão et al. 2013). Therefore, the literature contains several studies using this modeling option (Huang et al. 2006; Abu-Hammad et al. 2007; Barão et al. 2013). In future, with technological advances, it is probably that this modeling will not be performed since these changes affect the stress/strain distribution patterns near from implants, which can act as a potential methodological bias when the bone tissue is the focus of the analysis. Thereby, the results of studies that use this modeling option should be carefully analyzed, in particular those studies that evaluate the stress and strain distribution in the bone tissue and draw conclusions based in the using the simplification with total elimination of the threads.

\section{Conclusion}

Within the limitations of this study, the following conclusions can be drawn:

The modeling for simplification of the implant surface was able to alter the stress and strain distribution on the cortical bone.

The total elimination of the threads in the CAD provided by the implant company should be avoided when the aim of study is to evaluate the stress transferred to the cortical bone.

Slightly simplification of the implant sustaining the threads in the CAD provided by the implant company can be performed, as this does not influence the stress and strain distribution on the cortical bone tissue.

\section{Acknowledgements}

The authors would like to express gratitude to Sao Paulo Research Foundation - FAPESP, Brazil [grant number 2011/01045-2], National Counsel of Technological and Scientific Development - CNPq, Renato Archer Research Center, Campinas, SP, Brazil, Conexão Sistemas de Prótese, Arujá, São Paulo, Brazil.

\section{Disclosure statement}

No potential conflict of interest was reported by the authors.

\section{References}

Abu-Hammad O, Khraisat A, Dar-Odeh N, Jagger DC, Hammerle CH. 2007. The staggered installation of dental implants and its effect on bone stresses. Clin Implant Dent Relat Res. 9:121-127.

Barão VAR, Delben JA, Lima J, Cabral T, Assunção WG. 2013. Comparison of different designs of implant-retained overdentures and fixed full-arch implant-supported prosthesis on stress distribution in edentulous mandible a computed tomography-based three-dimensional finite element analysis. J Biomech. 46:1312-1320.

Choi AH, Conway RC, Ben-Nissan B. 2014. Finite-element modeling and analysis in nanomedicine and dentistry. Nanomedicine. 9:1681-1695.

Chowdhary R, Halldin A, Jimbo R, Wennerberg A. 2013. Evaluation of stress pattern generated through various thread designs of dental implants loaded in a condition of immediately after placement and on osseointegration - an FEA study. Implant Dent. 22:91-96.

Chung SH, Heo SJ, Koak JY, Kim SK, Lee JB, Han JS, Han CH, Rhyu IC, Lee SJ. 2008. Effects of implant geometry and surface treatment on osseointegration after functional loading: a dog study. J Oral Rehabil. 35:229-236.

Dayrell AC, Noritomi PY, Takahashi JM, Consani RL, Mesquita MF, dos Santos MB. 2015. Biomechanical analysis of implant-supported prostheses with different implantabutment connections. Int J Prosthodont. 28:621-623.

de Faria Almeida DA, Pellizzer EP, Verri FR, Santiago JF, de Carvalho PS. 2014. Influence of tapered and external hexagon connections on bone stresses around tilted dental implants: three-dimensional finite element method with statistical analysis. J Periodontol. 85:261-269.

Eraslan O, Sevimay M, Usumez A, Eskitascioglu G. 2005. Effects of cantilever design and material on stress distribution in fixed partial dentures - a finite element analysis. J Oral Rehabil. 32:273-278.

Fuh LJ, Hsu JT, Huang HL, Chen MY, Shen YW. 2013. Biomechanical investigation of thread designs and interface conditions of zirconia and titanium dental implants with bone: three-dimensional numeric analysis. Int $\mathrm{J}$ Oral Maxillofac Implants. 28:e64-e71.

Hoshaw SJ, Brunski JB, Cochran GVB. 1994. Mechanical loading of Brånemark implants affects interfacial bone modeling and remodeling. Int J Oral Maxillofac Implants. 9:345-360.

Huang HL, Chang CH, Hsu JT, Fallgatter AM, Ko CC. 2007. Comparison of implant body designs and threaded designs 
of dental implants: a 3-dimensional finite element analysis. Int J Oral Maxillofac Implants. 22:551-562.

Huang HL, Hsu JT, Fuh LJ, Tu MG, Ko CC, Shen YW. 2008. Bone stress and interfacial sliding analysis of implant designs on an immediately loaded maxillary implant: a nonlinear finite element study. J Dent. 36:409-417.

Huang HL, Lin CL, Ko CC, Chang CH, Hsu JT, Huang JS. 2006. Stress analysis of implant-supported partial prostheses in anisotropic mandibular bone: in-line versus offset placements of implants. J Oral Rehabil. 33:501-508.

Kinoshita H, Nakahara K, Matsunaga S, Usami A, Yoshinari M, Takano N, Ide Y, Abe S. 2013. Association between the peri-implant bone structure and stress distribution around the mandibular canal: a three-dimensional finite element analysis. Dent Mater J. 32:637-642.

Kitamura E, Stegaroiu R, Nomura S, Miyakawa O. 2004. Biomechanical aspects of marginal bone resorption around osseointegrated implants: considerations based on a threedimensional finite element analysis. Clin Oral Implants Res. 15:401-412.

Liang R, Guo W, Qiao X, Wen H, Yu M, Tang W, Liu L, Wei Y, Tian W. 2015. Biomechanical analysis and comparison of 12 dental implant systems using 3D finite element study. Comput Methods Biomech Biomed Eng. 18:1340-1348.

Limbert G, van Lierde C, Muraru OL, Walboomers XF, Frank M, Hansson S, Middleton J, Jaecques S. 2010. Trabecular bone strains around a dental implant and associated micromotions - a micro-CT-based three-dimensional finite element study. J Biomech. 43:1251-1261.

Lofaj F, Kučera J, Németh D, Kvetková L. 2015. Finite element analysis of stress distributions in mono- and bi-cortical dental implants. Mater Sci Eng C Mater Biol Appl. 50:85-96.

Matsunaga S, Naito H, Tamatsu Y, Takano N, Abe S, Ide Y. 2013. Consideration of shear modulus in biomechanical analysis of peri-implant jaw bone: accuracy verification using image-based multi-scale simulation. Dent Mater J. 32:425-432.
Moraes SL, Pellizzer EP, Verri FR, Santiago Jr JF, Silva JV. 2015. Three-dimensional finite element analysis of stress distribution in retention screws of different crown-implant ratios. Comput Methods Biomech Biomed Eng. 18:689-696.

Pellizzer E, Santiago Junior JF, Villa L, de Souza Batista V, de Mello C, de Faria Almeida D., Honório H. 2014. Photoelastic stress analysis of splinted and unitary implant-supported prostheses. Applied Physics B. 117:235-244.

Pessoa RS, Bezerra FJ, Sousa RM, Vander Sloten J, Casati MZ, Jaecques SV. 2014. Biomechanical evaluation of platform switching: different mismatch sizes, connection types, and implant protocols. J Periodontol. 85:1161-1171.

Ramos Verri F, Santiago Junior JF, de Faria Almeida DA, de Oliveira GB, de Souza Batista VE, Marques Honorio H, Yoshito Noritomi P, Piza Pellizzer E. 2015. Biomechanical influence of crown-to-implant ratio on stress distribution over internal hexagon short implant: 3-D finite element analysis with statistical test. J Biomech. 48:138-145.

Sallam H, Kheiralla LS, Aldawakly A. 2012. Microstrains around standard and mini implants supporting different bridge designs. J Oral Implantol. 38:221-229.

Sotto-Maior BS, Mercuri EG, Senna PM, Assis NM, Francischone CE, Del Bel Cury AA. 2016. Evaluation of bone remodeling around single dental implants of different lengths: a mechanobiological numerical simulation and validation using clinical data. Comput Methods Biomech Biomed Eng. 19:699-706.

Tiossi R, Vasco MA, Lin L, Conrad HJ, Bezzon OL, Ribeiro RF, Fok AS. 2013. Validation of finite element models for strain analysis of implant-supported prostheses using digital image correlation. Dent Mater. 29:788-796.

Xiao JR, Li YF, Guan SM, Song L, Xu LX, Kong L. 2011. The biomechanical analysis of simulating implants in function under osteoporotic jawbone by comparing cylindrical, apical tapered, neck tapered, and expandable type implants: a 3-dimensional finite element analysis. J Oral Maxillofac Surg. 69:e273-e281. 